\title{
Dormancy break with garlic extract and hydrogen peroxide in rootstock vine 'SO4'
}

\author{
Juan Saavedra del Aguilla ${ }^{a}$, Nádia Cristiane Alves Vianna, Marcelo Souza Soares, Andressa Silveira Meinerz, \\ Elisandra Nunes da Silva and Elizeu Fernandes Nogueira
}

Federal University of Pampa (UNIPAMPA) - "Dom Pedrito" Campus - Course of Bachelor's Degree in Oenology. Address: Street Vinte e Um de Abril n 80, "Dom Pedrito", "Rio Grande do Sul” (RS), CEP 96450-000, Brazil

\begin{abstract}
A synthetic product is used to help overcome dormancy of the buds of vines in tropical and subtropical climate, but the product currently available in Brazil has the highest level of toxicity to humans. The objective was to study some alternatives to break the dormancy of the buds of the rootstock vine 'SO4'. The sprayed treatments were: $\mathrm{T} 1=$ water (control); $\mathrm{T} 2=$ hydrogen cyanamide $(3 \%)$; $\mathrm{T} 3=$ garlic $(33 \%)$ and; $\mathrm{T} 4=$ Hydrogen Peroxide $-\mathrm{H}_{2} \mathrm{O}_{2}-(3 \%)$. The cuttings were immersed in a indole acetic acid (IAA) of $5 \mathrm{ppm}$ for 15 seconds and placed in plastic bags $(19 \mathrm{~cm} \times 5 \mathrm{~cm} \times 8 \mathrm{~cm})$ with $50 \%$ sand $+50 \%$ commercial substrate (H. Decker $\left.{ }^{\circledR}\right)$. After 04 months, were evaluated: percentage of live cuttings, aerial part height $(\mathrm{cm})$, length of roots $(\mathrm{cm})$ and dry matter of aerial parts and root $(\mathrm{g})$. Regarding the roots, root dry weight and dry matter of aerial parts, stood out the cuttings treated with $\mathrm{H}_{2} \mathrm{O}_{2}$ at a concentration of $3 \%$ (T4). In the present work conditions, preliminarily concluded that $\mathrm{H}_{2} \mathrm{O}_{2}$ at a concentration of $3 \%$ can assist in breaking dormancy of the buds of the roostock vine 'SO4'.
\end{abstract}

\section{Introduction}

The vine is a fruit plant of temperate climate that develops according to the means in which it operates. Currently has been planted 81,000 ha in Brazil [1]. This plant has the annual life cycle divided into three periods which are: rest period where it loses its leaves and enters latency; growth period which happens the sprouting, is where the physiological awakening with sprouting leaves occurs, flowering, production, sap circulation and finally; the elaboration period, with formation and ripening of fruits, as well as the leaves fall.

Studies report that is necessary for breaking dormancy in the vine a cold period of 50 to 400 hours at temperatures below $7^{\circ} \mathrm{C}$ depending on the cultivar; responses to low temperatures are varied according to the health, nutrition and age of buds and influence the growth and survival of plants [2].

Dormancy of the buds can be classified in three types: parodormancy, endodormancy and ecodormancy. The endodormancy happens in regions where there is cold in the winter months, characterized by paralysis of the gem development due to biochemical and physiological events that take place in buds. The parodormancy occurs during the vegetation cycle, plant production and results from the influence of other plant organs on the bud, more known as apical dominance. Finally the ecodormancy occurs after the winter period where the buds outweigh the endodormancy and corresponds to budding limitation when the conditions of temperature and water availability are not favorable [2].

\footnotetext{
a e-mail: juanaguila@unipampa.edu
}

The state endodormancy is reached when the vine at the end of the season, loses its leaves. Certain physiological behavior is necessary for plants to begin a new cycle in the spring, and therefore surviving in low temperatures. In tropical conditions the vines do not trigger the endodormancy by the absence of cold, so only occur paradormancy (with a predominance of apical sprout and continuous vegetative growth) and ecodormancy (coordinated by water availability) [2].

The active ingredient currently used in Brazil to break dormancy in grapevine is hydrogen cyanamide $\left(\mathrm{H}_{2} \mathrm{CN}_{2}\right)$, it should be sprayed on the buds at doses that may vary depending on the location, cultivate, plant vigor, sun, accumulated chill hours, the time of pruning and bud dormancy stage.

Brazil is the largest consumer of the world's pesticides since 2009, within the pesticides, the $\mathrm{H}_{2} \mathrm{CN}_{2}$ is the active ingredient in the commercial product Dormex ${ }^{\circledR}$, the growth regulators class with rating Toxicology I Extremely Toxic, at the time in the world has this unique pesticide, in Brazil it is legally registered for use on dormancy breaking of buds in various types of fruits, including the vines; depending on weather conditions (temperature) of the tropical and sub-tropical regions, the use of this regulator is essential. For the toxicity of this product, alternatives are sought that can break dormancy of buds of vine, as well as being less toxic or harmless to man and the environment.

In this search for alternatives to $\mathrm{H}_{2} \mathrm{CN}_{2}$, studies report that garlic extract and hydrogen peroxide can become products applied on the buds that enable the dormancy breaking of them [3], with uniformity, accuracy and production. 
The garlic extract also helps in breaking dormancy of these buds through accumulative oxidative stress of hydrogen peroxide $\left(\mathrm{H}_{2} \mathrm{O}_{2}\right)$, which is overcoming satisfactory numbness and without causing phyto-toxicity.

It is known that hydrogen peroxide is who initiates the signal transduction process whose result is the end of the dormancy of the buds; the plant produces naturally a $\mathrm{H}_{2} \mathrm{O}_{2}$ dose applied directly to the gem allows this process to occur more frequently indicating that it needs to wake up to realize the growth stages necessary for the development of the plant and start of a new cycle [4].

Accordingly, the this study aimed alternatives to the existing commercial product, which can assist in vine sprouting, with uniformity, for it was used rootstock vine 'SO4' as physiological model study.

\section{Materials and methods}

This work was by the Core of Study, Research and Extension in Oenology $\left(\mathrm{NEPE}^{2}\right)$ from the Course of Bachelor's degree in Oenology, "Dom Pedrito" Campus of the Federal University of "Pampa". For the experiment were used cuttings of grapevine rootstock 'SO4' collected in the region of "Dom Pedrito", RS, Brazil in September of 2015. The cuttings of rootstock 'SO4' were immersed in $5 \mathrm{ppm}$ of auxin (IAA) for 15 seconds after they were planted in plastic bags $(19 \mathrm{~cm} \times 5 \mathrm{~cm} \times 8 \mathrm{~cm})$ containing $50 \%$ sand $+50 \%$ commercial substrate $($ H. Decker $)$.

The experiment consisted of four treatments, with four replicates per treatment and, 12 cuttings per repetition, totaling 48 cuttings per treatment and 192 cuttings for the entire experiment.

The treatments were: $\mathrm{T} 1=\mathrm{Gem}$ spraying with water (control); T2=gem spraying with cyanamide hydrogenated at a concentration of $3 \%$; $33=$ spraying garlic at a concentration of $36 \%$ and; $\mathrm{T} 4=$ spraying Hydrogen Peroxide at a concentration of $3 \%$.

Daily were measured temperature and air relative humidity (minimum and maximum), and daily monitoring the bud sprouting, also held irrigation of plants when needed.

After the four-month period were evaluated the percentage of live cuttings; aerial part height $(\mathrm{cm})$; root height (c m); fresh root weight $(\mathrm{g})$; fresh weight of aerial part $(\mathrm{g})$; roo dry mass $(\%)$ and; dry mass of aerial part $(\%)$.

Was performed the analysis of variance (ANOVA) and where appropriate, the comparison Tukey's test at the 5\% probability $[5,6]$.

\section{Results ans discussions}

It was observed that the rootstock cuttings 'SO4' of the T4 treatment (hydrogen peroxide to $3 \%$ ) had a greater number of bud break (93\% buds of the plant) (Fig. 1). A week after the cuttings of rootstock ' $\mathrm{SO} 4$ ' being planted, they began to sprout, and were monitored daily by a range of phenological state [7].

After the dormancy was broken, the plants developed; T4 treatment, remained in evidence, being significantly higher than others in the variable aerial part height response (Fig. 2).

The leaf development is due to photosynthesis, a process performed by plants to produce their own food, which consists mainly of glucose. As it produces glucose, eliminates oxygen. This is used in their

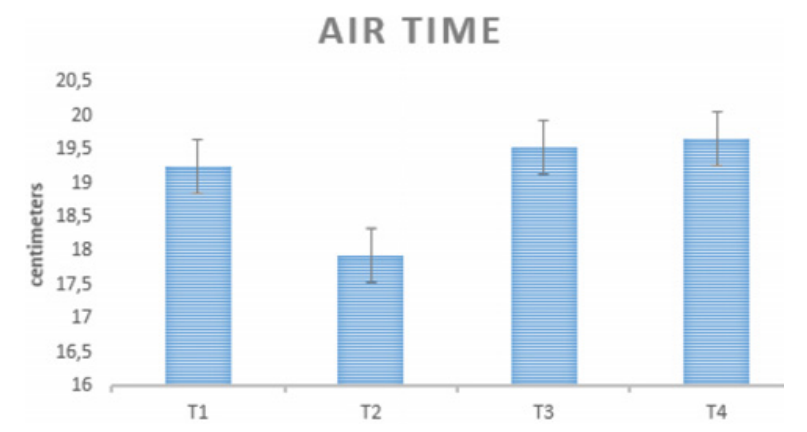

Figure 1. Budding buds 'SO4'. T1 - distilled water (control); $\mathrm{T} 2-3.0 \%$ of hydrogen cyanamide; $\mathrm{T} 3-33 \%$ garlic extract; T4 $-3,0 \%$ and hydrogen peroxide. Vertical bars represent \pm S.D. $(n=48)$.

\section{LENGTH PART RADIICULAR}

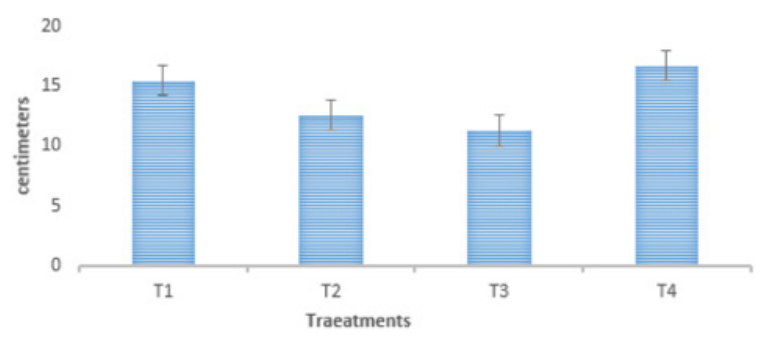

Figure 2. Air time $(\mathrm{cm})$ 'SO4', T1 - distilled water (control); $\mathrm{T} 2-3.0 \%$ of hydrogen cyanamide; T3-33\% garlic extract; T4 $-3.0 \%$ and hydrogen peroxide. Vertical bars represent \pm S.D. $(n=48)$.

\section{ROOT DRY WEIGHT}

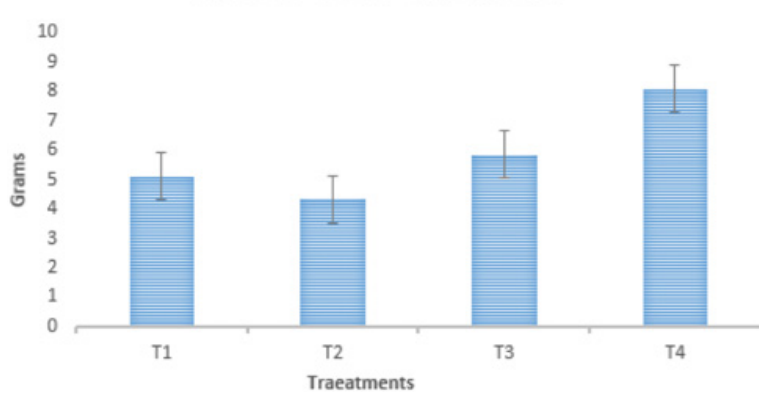

Figure 3. Length part radicular (cm) 'SO4', T1 - distilled water (control); $\mathrm{T} 2-3.0 \%$ of hydrogen cyanamide; T3 - 33\% garlic extract; $\mathrm{T} 4-3,0 \%$ and hydrogen peroxide. Vertical bars represent \pm S.D. $(n=48)$.

metabolic pathways. Root growth, depends on a constant photosynthetic products supply from the aerial part, and the redistribution of carbohydrates to root depends on its storage capacity compared to other plant organs [8].

The root length of the 'SO4' rootstock and dry mass of the aerial part, is due to the fact of breaking dormancy of the buds occurs in the period necessary to perform photosynthesis (Figs. 4 and 5).

According to studies, it was found that the application of garlic extract the gems in different dosages had no effect on breaking dormancy, but in the number of sprouted buds at the end of the experiments [9].

In treatments cuttings of 'Cabernet Sauvignon', where they were subjected to cold, they showed the need for hours of cold to break dormancy from induction [10]. In a view to other reported studies on dormancy breaking, may have been influenced by the time of harvest cuttings where they were in a state of deep endodormancy is no longer possible to occur budding [11]. 


\section{DRY MASS AEREA}

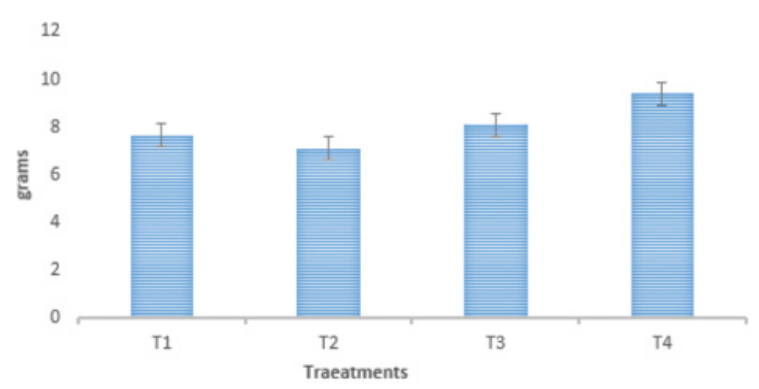

Figure 4. Root dry weight (g) 'SO4', T1 - distilled water (control); $\mathrm{T} 2-3.0 \%$ of hydrogen cyanamide; T3 - 33\% garlic extract; $\mathrm{T} 4-3,0 \%$ and hydrogen peroxide. Vertical bars represent \pm S.D. $(n=48)$.

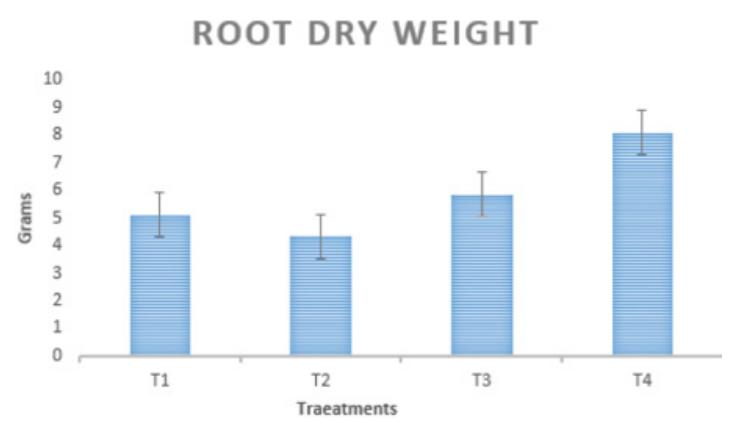

Figure 5. Dry mass aérea (g) 'SO4', T1 - distilled water (control); $\mathrm{T} 2-3.0 \%$ of hydrogen cyanamide; $\mathrm{T} 3-33 \%$ garlic extract; $\mathrm{T} 4-3,0 \%$ and hydrogen peroxide. Vertical bars represent \pm S.D. $(n=48)$.

In plants where the summers are cold because of the altitude, where occurs the cold hours deficiency, studies should be performed due to the dormant time [12].

Already in temperate climate plants the release of the main mechanisms that make it possible to break dormancy by oxidative stress with hydrogen peroxide, activate gene expression by activating the break dormancy [13].

Therefore the use of hydrogen peroxide in the bud sprouting accelerates through the hydrolysis carried out by the plant, even if the cold hours of the sum was less than the essential plant could overcome dormancy because the protective metabolism thereof.

However it is necessary carry out new research, experiments with different concentrations of hydrogen peroxide or the same in consecutive years for full confirmation and effectiveness of the need for alternatives to pesticides available at the moment in Brazilian market.

\section{Conclusion}

Based on the results obtained and the conditions of this experiment, preliminarily concludes that the hydrogen peroxide at a concentration of $3 \%$ can assist in overcoming the dormancy breaking in the rootstock vine 'SO4'.

We would like to thank to wine grower Mr. Adair Camponogara.

\section{References}

[1] M. Vitor.; Miele, A.; Rizzon, L.A.; Barradas, C.I.N. Composição físico-química do vinho Cabernet Franc proveniente de videiras conduzidas no sistema lira aberta. Ciência e Tecnologia de Alimentos, v. 26, n. 2, p. 290-296, 2006M. Ben Rabha, M.F. Boujmil, M. Saadoun, B. Bessaïs, Eur. Phys. J. Appl. Phys. (to be published)

[2] Pérez, F.J., Lira, W. (2005) Possible role of catalase in post-dormancy bud break of grapevines. Journal of Plant Physiology 162:301-308M

[3] J. Saavedra del Aguila; A.P. Dachi; E.N. Fernandes; B.L. Hamm; F.C. de Almeida; J.M. Silveira. Garlic and $\mathrm{H}_{2} \mathrm{O}_{2}$ in overcoming dormancy on the vine 'Cabernet Sauvignon', France, Bio Web of Conferences, v. 5 , 3p. (2015)

[4] Godon, C., Lagniel, G., Lee, J., Buhler, J., Kieffer, S., Perrot, M., Boacherie, H., Toledo, M.B., Labarre, J. (1998) The $\mathrm{H}_{2} \mathrm{O}_{2}$ stimulon in sacharomyces cervisiae. J Biol Chem., 273:22480-22489

[5] F.C. de Almeida; J.F.L. de C. Cham; B.L. Hamm; S.M. Ferreira; M. Gabbardo; J. Saavedra del Aguila. Use of plant growth regulation in the conservation of grapes 'Italy' as aid postharvest, France, Bio Web of Conferences, v. 3 , 4p. (2014)

[6] J. Saavedra del Aguila; A. Zanella; A.D. Pinheiro; A.M. dos Santos; E.B. Radmann; L.S. Heiffigdel Aguila, Woody cuttings of 'Niagara Rosada' and 'Niagara Branca' rustic grapes. Wageningen, Holanda. Acta Horticulturae, v. 1115, p. 249-252 (2016).L. T. De Luca, Propulsion physics (EDP Sciences, Les Ulis, 2009)

[7] Von. K. W. Eichhorn, D. H. Lorenz. Phenological Development Stage of the Grapevine, Institut fur Grenzflachen, 29 (1977)

[8] Kriedemann, P.E.; Loveys, B.R.; Downton, W.J.S. Internal control of stomatal physiology and photosynthesis. II. Photosynthetic responses to phaseic acid. Australian Journal of Plant Physiology, Victoria, v.2, p.553-567, 1975

[9] Zanette, F.; Carvalho, R.I.N.; Dron, C. Effect of low temperature on dormancy intensity in one, two and three years-old-buds of apple tree. Short Communications of Second International Symposium on Plant Dormancy, Angers, France, p. 13-17, 2000

[10] Botelho, R.V.; Pavanello, A.P.; Pires, E.J.P.; Terra, M.M.; Muller, M.M.L. Effects of chilling and garlic extract on bud dormancy release in Cabernet Sauvignon grapevine cuttings. American Journal of Enology and Viticulture, Davis, v. 58, p. 402-404, 2007

[11] Lavee, S.; May. P. Dormancy of grapevine buds - facts and speculation. Australian Journal of Grape and Wine Research, Kyoto, v. 3, p. 31-46, 1997

[12] Kubota, N.; K. Toriu; Y. Yamane; T. Kawazu; T. Higuchi y S. Nishimura. 2003. Identification of active substances in chinese chive and rakkyo plants responsible for breaking bud dormancy in grape cuttings. J. Jap. Soc. Hort. Sci. 72(4), 268-274

[13] Pinto, M.; W. Lira; H. Uglder y F. Perez. 2003. Fisiologia de la latência de las yemas de vid: Hipotéses actuales. Universidad de Chile. $16 \mathrm{p}$

[14] F. De Lillo, F. Cecconi, G. Lacorata, A. Vulpiani, EPL, 84 (2008)

[15] L. T. De Luca, Propulsion physics (EDP Sciences, Les Ulis, 2009) 